Please do not remove this page

RMIT

UNIVERSITY

\title{
Using social data in strategic environmental assessment to conserve biodiversity
}

Ives, Christopher; Biggs, Duan; Hardy, Mathew; Lechner, Alex; Wolnicki, Mateusz; Raymond, Christopher https://researchrepository.rmit.edu.au/esploro/outputs/9921862562901341/filesAndLinks?institution=61RMIT_INST\&index=null

Ives, C., Biggs, D., Hardy, M., Lechner, A., Wolnicki, M., \& Raymond, C. (2015). Using social data in strategic environmental assessment to conserve biodiversity. Land Use Policy, 47, 332-341.

https://doi.org/10.1016/j.landusepol.2015.04.002

Document Version: Accepted Manuscript

Published Version: https://doi.org/10.1016/j.landusepol.2015.04.002

Repository homepage: https://researchrepository.rmit.edu.au

(c) 2015 Elsevier Ltd. All rights reserved.

Downloaded On 2023/04/26 13:00:27 +1000

Please do not remove this page 
Thank you for downloading this document from the RMIT Research Repository.

The RMIT Research Repository is an open access database showcasing the research outputs of RMIT University researchers.

RMIT Research Repository: http://researchbank.rmit.edu.au/

\section{Citation:}

Ives, C, Biggs, D, Hardy, M, Lechner, A, Wolnicki, M and Raymond, C 2015, 'Using social data in strategic environmental assessment to conserve biodiversity', Land Use Policy, vol. 47, pp. 332-341.

See this record in the RMIT Research Repository at:

https://researchbank.rmit.edu.au/view/rmit:33211

Version: Accepted Manuscript

\section{Copyright Statement:}

(C) 2015 Elsevier Ltd. All rights reserved.

This work is licensed under a Creative Commons Attribution 4.0 International License.

\section{Link to Published Version:}

http://dx.doi.org/10.1016/j.landusepol.2015.04.002 
Integrating Social Data into Strategic Environmental Assessment of Land Use

Plans to Improve Biodiversity Conservation

4 Abstract

5 Strategic Environmental Assessment (SEA) is increasingly used to assess land use plans in a way

6 that is broader in spatial, temporal and conceptual scope than traditional Environmental Impact 7 Assessment (EIA). Meanwhile, conservation scientists have recognised that successful biodiversity 8 conservation relies on the social feasibility of conservation actions in addition to possessing 9 information about biological priorities. SEA provides a framework for integrating information regarding the social feasibility of conservation actions with supporting environmental legislation in

11 order to achieve enhanced conservation outcomes. In this paper we argue that data on the social 12 context of land use plans are vital to ensuring effective biodiversity conservation outcomes that 13 result from SEAs. We explore the Australian Environment Protection and Biodiversity 14 Conservation Act (1999) (EPBC Act) as a case study of how the integration of these data can be practically achieved within an existing legal process. While a range of social data is relevant to this type of assessment, we focus on the use of spatially-referenced social data in the context of land use planning. When applied to the design and implementation of land use plans, this type of information can improve the acceptability of conservation actions, enhance environmental stewardship, and minimise land use conflict through taking stock of the values and attitudes (precursors to behaviour) that are relevant to proposed land use change and conservation action. Through exploring the integration of these data into each of the stages of SEA under the EPBC Act, we show that opportunities exist to strengthen the effectiveness of SEA in delivering conservation outcomes without altering existing legal processes. 


\section{Introduction}

Assessing the environmental impacts of land use is a standard policy approach of jurisdictions around the world. Environmental Impact Assessment (EIA) is the earliest form of this and is today a tenet of environmental regulation. Since the 1990’s, however, Strategic Environmental Assessment (SEA) has increased in prominence (Tetlow and Hanusch, 2012). SEA extends the scope of EIA, moving beyond a focus on isolated actions to also include policies, plans or programs (Partidário, 2000, 1996) and shifts the assessment of impacts to higher orders of decision-making (Tetlow and Hanusch, 2012). For these reasons, SEA has been praised for its ability to consider multiple impacts over much longer time periods and influence the choice of alternative development options rather than simply documenting expected environmental decline (Partidário, 2000, 1996; Tetlow \& Hanusch, 2012). This is particularly important for biodiversity conservation, as traditional individual project assessments have been criticised for their inability to account for cumulative impacts within a larger socio-political context (Partidário, 2000; Slootweg et al., 2001). In contrast to EIA, SEA can "identify threats and opportunities for biodiversity at an earlier stage in the decision-making process” (Treweek et al., 2005, p. 175). Many jurisdictions around the world have therefore adopted elements of SEA as a means of protecting species and environments of national significance that are threatened by large-scale human actions, such as regional plans for urban development or resource extraction (Ng and Obbard, 2005; Uprety, 2005).

Since the 1990s, the field of conservation science has also gained increased prominence. This field explores the ecological and socio-economic factors associated with conserving wild nature (Kareiva and Marvier, 2012). Recent conservation science literature has recognised that good outcomes often depend more on favourable social conditions that enable implementation of actions (including human values, attitudes, behaviours and political conditions), than on accurate ecological information (Ban et al., 2013; Knight et al., 2006, 2008; Knight and Cowling, 2007; Pretty and 
53 Smith, 2004; Raymond and Brown, 2011). Much of this research has focused on conservation 54 planning (the identification and prioritisation of areas for conservation action) and direct community actions, with little exploration of the role of legal instruments and policies which are important drivers of biodiversity conservation. There is a need therefore to explore the capacity of SEA to utilise insights from recent conservation research, through incorporating data on the social determinants of biodiversity outcomes within the assessment process.

Although social and economic factors are increasingly being considered within SEA (MorrisonSaunders and Fischer, 2006; Vanclay, 2004), when it comes to evaluating impacts to biodiversity, SEA applications around the world remain focused on the physical determinants of environmental damage with little consideration of how social factors might influence conservation outcomes. Treweek et al. (2005) stress that biodiversity impacts "may be influenced by social, economic and political factors" and that these "must be taken into account”. This same sentiment was expressed by The International Association for Impact Assessment (2002) which held that SEA should address the interrelationships between biophysical, social and economic impacts rather than focusing on environmental impacts alone. Relevant data on socio-demographic changes, stakeholder values and behaviour or land use conflicts could help decision-makers identify both opportunities for conservation gains within landscapes, and potential threats that may impede conservation efforts (see Brown and Raymond, 2014; Ives and Kendal, 2014).

The widespread use, breadth and inherent flexibility of SEA approaches make for an ideal opportunity to analyse how social data can be systematically considered alongside biophysical data in land use policy. At present there are no standard guidelines regarding the methods that should be used in SEA; each assessment should apply techniques appropriate to the context (Noble, 2012). This flexibility is a strength of SEA, yet can also mean that practitioners are unsure as to how gather and implement appropriate data (Noble, 2012). Conservation feasibility refers to the likelihood of 
an action leading to an effective and sustained conservation outcome, and is a concept that is increasingly referenced in the conservation literature. However, there is currently no guidance on how social data on conservation feasibility might be included within SEA. This has implications for the assessment of the social acceptability and feasibility of land-use policies which aim to mitigate or offset the environmental impacts of new developments. We demonstrate here how spatially mapped social data can fit neatly into existing methods for SEA, thereby addressing the "need for more systematic methodologies with guidance on methods selection at different SEA tiers and in different contexts” (Noble, 2012; p145).

In this article, we draw upon the Australian Strategic Assessment legislation (under the Environment Protection and Biodiversity Conservation Act 1999 (Cth)) as a case study of how including social data in SEA can enhance conservation outcomes. Since SEAs have been most frequently and successfully applied to land use plans (Tetlow and Hanusch, 2012), we focus our discussion on spatial land use planning assessment, considering in particular how the mapping of social values might enhance SEA in this context. Although the social impacts of plans are important on social justice and democratic grounds (Vanclay, 2003), our concern is specifically how social dynamics might affect conservation outcomes. The emphasis of this article is thus on how to improve the 'substantive effectiveness' of SEA (see Chanchitpricha and Bond, 2013), measured by tangible biological outcomes rather than the procedural or transactive outcomes (e.g. improvement of policy process) that have been addressed by other authors (e.g. Sadler, 1996). After outlining how SEA functions in Australia, we develop a framework for systematically considering social data alongside potential impacts to nationally-listed threatened species. We conclude by discussing the key lessons from this application and discuss general principles for considering social data in SEA. 


\section{Australian Strategic Environmental Assessment in a Global Context}

The broad definition of SEA means that it takes different forms across a diversity of countries.

Despite a theoretical focus on strategic consideration of long-term scenarios and participatory decision-making among stakeholders, application of SEA in Australia, along with many other jurisdictions, is tethered closely to EIA philosophy and is motivated by legal requirements to report on specific impacts) (see Lobos and Partidario, 2014). The legal weight behind SEA in Australia is the Environment Protection and Biodiversity Conservation Act 1999 (Cth) (EPBC Act). It provides for both single project focus EIA (Parts 7, 8 and 9) and the broader approach of SEA (Part 10) called 'Strategic Assessment'. Under the EPBC Act, the delegated Government Minister has ultimate power to approve or reject a development proposal likely to have a significant impact on Matters of National Environmental Significance (MNES) (such as threatened species and ecological communities).

The EPBC Act's Strategic Assessment provisions differ from EIA in that they consider the impacts on MNES from a series of proposals or developments across larger temporal and spatial scales, rather than an individual project (DSEWPAC, 2012). This can permit development across a larger area without further need for individual project assessments (DSEWPAC, 2012; Early, 2008). The inclusion of Part 10 in the EPBC Act signified the first formal adoption of SEA into Australia's national environmental law (Early, 2008; Marsden, 2013) and is increasingly being used.

Application of SEA in Australia is interesting in the international context for two reasons. First, the location of Strategic Assessment provisions within the EPBC Act means that the impact significance of a proposal is measured entirely against impacts to MNES, although the Minister must consider economic and social factors related to the proposed action (Macintosh, 2009). This narrow focus on environmental concerns is similar to New Zealand practice where The Resource 
Management Act is concerned primarily with assessment of environmental impacts of projects. This

131 differs from the UK and many European countries that typically consider broader sustainability concerns (Jones et al., 2005). Second, there is no legal requirement for a Strategic Assessment to be undertaken. This differs from most European countries where an SEA is mandatory for land use plans under the European Union Strategic Environmental Assessment Directive. However, the steps that constitute a Strategic Assessment in Australia once entered into are formalised and more highly regulated than the flexible approach taken in other countries (e.g. Canada) (Tetlow \& Hanusch, 2012; Jones et al., 2005).

Many applications of SEA are strongly intertwined with public consultation and participation

140 (Gauthier et al., 2011; Rauschmayer \& Risse, 2005) and may incorporate Social Impact Assessment 141 (Vanclay, 2003). However, this is not formalised in the Australian context as a result of Strategic 142 Assessment originating from within more traditional EIA legislation. Different countries 143 incorporate public participation at different stages of the SEA process, for example plan 144 development (New Zealand), screening and scoping (Ireland) and after the report has been prepared 145 (UK) (Jones et al., 2005). What we propose in this article is different from participatory approaches 146 where stakeholders are directly included in the decision-making process. While we recognise the 147 importance of public participation within impact assessment, it is sometimes difficult to initiate for 148 practical and political reasons. Instead we focus here on how quantitative social data on 149 conservation feasibility might be included in SEA processes that are data-driven and largely 150 positivist in their approach. We aim to strike a balance between what may be an ideal 151 operationalisation of SEA and what is practically achievable. Our approach does not exclude the 152 use of participatory approaches or SIAs, but may be used alongside these existing methods. We 153 outline here a novel way of incorporating social data related to conservation outcomes into every 154 stage of an SEA process, thereby enhancing the protection of biodiversity without requiring 155 dramatic transformation of current legislated processes. 


\section{How does a Strategic Assessment Work?}

158

159 Under the EPBC Act, Strategic Assessments are undertaken within the broad framework of a 160 standard SEA process (UNEP, 2002). These stages are outlined below and summarised graphically 161 in Figure 1.

\subsection{Screening}

Strategic Assessments are a collaborative process where a relationship is developed between the consent authority administering the EPBC Act (i.e. the federal environment department acting on

behalf of the Minister) and the assessment partner (or proponent). Such collaboration starts at the earliest stages where screening is undertaken to assess whether a particular policy, plan or program should be subject to a Strategic Assessment (Early, 2008), based on a pre-determined set of criteria for identifying likely significant impact on MNES.

\subsection{Scoping}

The scoping stage is undertaken collaboratively to negotiate a formal agreement between the

175 Minister and the assessment partner as well as the terms of reference for the assessment process 176 (Marsden, 2013). This stage identifies important issues, how to examine them, and which guidelines to reference (DSEWPAC, 2012). Here, the assessment partner assists in developing common 178 expectations, key issues and matters for protection, availability of information, resourcing, timing 179 and governance arrangements. 
182 This stage is an iterative process of assessing impacts of a policy, plan or program on MNES. A 183 policy, plan or program and Strategic Assessment Report are developed by the assessment partner 184 and refined in consultation with the consent authority. The Strategic Assessment Report analyses 185 the potential impacts and outcomes of the policy, plan or program on MNES as well as any other 186 items listed in the terms of reference, such as state and regional issues (DSEWPAC, 2012). It 187 identifies potential alternatives to the proposal, and can also include elements of comparison 188 between these alternatives.

\subsection{Consideration of mitigation measures}

191 Once the scale of impact of the policy, plan or program has been determined, the assessment partner 192 and consent authority collaboratively look for ways to reduce the identified impacts to acceptable 193 levels. This could include avoidance, mitigation or compensatory actions, such as environmental 194 offsets (Macintosh, 2013).

\subsection{Reporting}

The reporting stage has three main priorities: (i) to document the findings of the assessment, the proposed alternatives and predicted impacts, (ii) to serve as a basis for consultation, and (iii) to provide recommendations for decision-makers, based on preferred alternatives and measures for 200 avoiding, minimising, mitigating and compensating for unavoidable impacts. Typically, the draft 201 policy, plan or program is released for comment by the assessment partner at the same time. 202 Following completion of public comment, the policy, plan or program and the Strategic Assessment 203 Report are finalised by the assessment partner. This process must take into account the comments 204 from the public and any advice from the consent authority. 
This stage is designed to act as a check on the adequacy of the information collected as part of the

208 Strategic Assessment process, including identification of bias, uncertainties and contradictory 209 findings. Once finalised to the satisfaction of the consent authority, the policy, plan or program and 210 the Strategic Assessment Report are submitted to the Minister for consideration (DSEWPAC, 211 2012). Endorsement occurs when the minister is satisfied that the policy, plan or program and the 212 associated Strategic Assessment Report adequately identify and address impacts on MNES, meets 213 the terms of reference and provides for any modifications recommended by the Minister. Although 214 endorsement does not always equate to an approval decision, it is a necessary step towards 215 approval.

\subsection{Decision making}

218 Following consideration of the matters raised in the Strategic Assessment, the Minister may 219 approve the taking of actions, allowing activities under the policy, plan or program to proceed 220 without the need for further federal approval of individual development proposals (Ashe and 221 Marsden, 2011). However, conditions may be attached to an approval if the Minister considers them 222 necessary. Critically, any decision must also take account of any relevant economic and social 223 matters of the plan, policy or program (EPBC Act, s146F).

\subsection{Monitoring and environmental auditing}

226 Monitoring and auditing is conducted by the assessment partner in relation to the mitigation 227 measures agreed to with the consent authority. This takes place beyond the decision-making stage 228 to ensure that the protection of MNES is upheld throughout the life of the Strategic Assessment 229 agreement (DSEWPAC, 2012). This can include monitoring both social and ecological change and the performance of agreed mitigation measures. 


\section{Social data relevant to Strategic Assessment of land use plans}

Social data are relevant to Strategic Assessments for their ability to inform the likelihood that biodiversity matters will be threatened as a result of a proposed plan (for example wildlife populations under pressure from increasing nearby urban populations) (Guerrero et al., 2010), or the feasibility of undertaking conservation actions on the landscape (such as establishing a biodiversity

offset reserve). These can be classified into three categories: (1) the individual determinants of conservation actions such as demographic characteristics, values, perceived risk, knowledge and access to income support (see Pannell et al., 2006; Raymond and Brown, 2011; Ticehurst et al.,

2011); (2) how social interactions (e.g. social networks) collectively influence biodiversity protection (Guerrero et al., 2013); and (3) the socio-political context in which decisions are made, such as laws and policies which regulate environmental action, or economic incentives and capacity building programs to affect behaviour change (Ban et al. 2013; Mills et al. 2013). Despite the importance of these data, they are not typically included in Strategic Assessments.

Data on the distribution and types of values that individuals assign to places is increasingly relevant to environmental decision-making. Such values are referred to as assigned, social or landscape values (Brown, 1984; Bryan et al., 2011; Ives and Kendal, 2014; Seymour et al., 2010). Knowledge of the composition of values for specific locations (such as recreational, aesthetic, or conservation values) can be used to infer relative social importance of these places and the degree of social acceptability of conservation or other land use activities (Brown and Raymond, 2014; Brown and Reed, 2012). Such data have been used to guide land-use decisions (Brown, 2012) and is known to shape conservation behaviours (Seymour et al., 2010). Land-use or development preference is an additional proxy for the feasibility of conservation because it reflects a desired end-state or future use of a particular area (e.g. use of land for residential, industrial, or tourism development), which may align with or oppose conservation efforts (Nielsen-Pincus et al., 2010). If local communities 
258 prefer development in or near an area of biological importance, the feasibility of future protection 259 of biodiversity in this area is low if decisions are made based upon social acceptance or political 260 grounds; in contrast, the feasibility of conservation is high if social values for conservation align 261 with these biologically important areas (Whitehead et al., in press). Public Participation GIS is one 262 effective and increasingly utilised method of assessing assigned values and development 263 preferences (Brown, 2012; 2005).

Data on spatially referenced landscape values offer four advantages if used together with the biophysical information typically considered in SEAs: (1) identification the level of compatibility between scientifically assessed conservation areas and areas of local value and concern; (2) prediction of potential conflict zones whereby different types or incommensurable values overlap; visual representation of the feasibility of plans to protect species of national importance (Raymond and Curtis, 2013).

\section{Opportunities for the application of social data in the Australian Strategic}

\section{Assessment process}

Below are ways in which social data can be used within the eight stages of Strategic Assessment (outlined in section 3) to enhance conservation outcomes.

\subsection{Screening and scoping (Stages 1 and 2)}

280 At present, social investigation within the Strategic Assessment process is generally limited to 281 expert consultation and engagement pertaining to the physical requirements of particular MNES, 282 with relatively little emphasis on broader community values. The screening and scoping phases 283 could be enhanced by utilising data on how social behaviours, attitudes, values and priorities relate 
to MNES, the proposed development and its anticipated environmental impacts (e.g. Curtis et al., 285 2005). For example, Raymond and Curtis (2013) used mail based surveys to identify key issues and opportunities with respect to regional sustainability planning in the Lower Hunter Valley in NSW, Australia. Such tools can provide baseline contextual information for drafting, negotiating and progressing the Strategic Assessment terms of reference. Moreover, understanding how people value and use species (e.g. for fishing) and habitats (e.g. wilderness recreation) is a critical first step to identifying socially-meaningful conservation priorities within an area (Ives and Kendal, 2014).

\subsection{Impact analysis and assessment - consideration of mitigation measures (Stages 3 and 4)}

During this phase social data can provide a benchmark against the terms of reference to identify community values and activities that are either beneficial or detrimental to protection of nationally protected species. While the persistence of biodiversity will in large part be due to physical factors such as habitat patch size, other social values, attitudes, behaviours (e.g. management regimes) and political/organisational structures are likely to exert great influence. For example, areas of ethnobiological significance, traditional hunting value, scenic quality, recreational importance and social well-being may relate positively to the protection of MNES, and should feature in the assessment report. Similarly, certain land use preferences, recreational activities, employment types and resource uses may conflict with conservation outcomes. Data on these positive or negative social influences can be collected via maps of aboriginal cultural landscapes (Ridges, 2006), visitor perceptions of park experiences, environmental impacts, and facilities (Brown and Weber, 2011), social values for natural capital and perceived threats (Bryan et al., 2011), and willingness of landholders to steward natural resources (Pasquini et al., 2010).

The assessment of impacts stemming from a proposed plan should consider indirect changes to biodiversity resulting from alteration of the social factors discussed above. For example, shifting 
310 the number of young families present within a region) could change how people interact with areas

311 of significant biodiversity, such as regional parks. Also, disruption of land management regimes 312 (e.g. hunting or fishing behaviours) can lead to ecological degradation, even though the 313 development associated with a proposal itself may not directly influence habitat. In terms of 314 mitigation and offsetting of impacts, social data such as willingness to sell for conservation 315 (Guerrero et al., 2010) and willingness to pay for environmental improvements (Brouwer et al., 316 2010), can also assist in developing options that will be biologically favourable and socially 317 sustainable.

\subsection{Public consultation and reporting stage (Stage 5)}

320 Public consultation can be modified to include evaluation the accuracy and adequacy of the social 321 data (collected at stages 1-4). Participatory mapping and modelling methods can also be used to 322 facilitate community engagement, accounting for the needs of multiple individuals or groups of 323 individuals (Lesslie, 2012; Voinov and Bousquet, 2010). The visualisation of impacts through 324 mapping data is particularly useful for this purpose.

\subsection{Review \& decision-making (Stages 6 and 7)}

Social information can inform the endorsement decision and the application of any necessary approval conditions. For example, an approval condition for a development impacting a threatened ecological community might include capacity building for the establishment of an Indigenous peoples bush foods industry, thereby creating a synergy between economic development, species protection and social licence to operate.

\subsection{Monitoring and environmental auditing stage (Stage 8)}

In addition to direct monitoring of legally protected matters, there is potential for ongoing 
persistence. For example, understanding the management capacity of local councils or nature reserve staff can provides assurance to the Minister that conservation outcomes for threatened species will be achieved. Finally, social data can be used to broadly assess the outcomes of Natural Resource Management (NRM) instruments used for avoiding, mitigating and offsetting environmental impacts (e.g. Curtis et al., 2008) and provide lessons for refining the current and 341 future Strategic Assessments.

\section{Potential barriers and challenges to the application of social data in Strategic}

\section{Assessment}

Although social matters are critical to achieving conservation success, there are a number of challenges that could affect the application of social information to the Strategic Assessment process.

\subsection{Data collection and integration}

The cost of data collection can pose an economic challenge to the use of social data in a Strategic Assessment. Mail-based surveys are costly and time-consuming compared with the collection of secondary data, such as that from publically available census databases. However, mail-based surveys enable a targeted assessment of community attitudes toward particular issues related to 356 biodiversity conservation, such as the impact of regional demographic change and property turnover on the adoption of natural resource management practices by landholders and the future viability of agricultural industries (Mendham and Curtis, 2010; Mendham et al., 2012). Regional census data only allows for extrapolations of the impact of developments on socio-demographic trends. 
One way to overcome the cost of social data collection is to interpolate self-reported social impacts

362 in the study area from known biophysical characteristics in related regions (Sherrouse et al., 2011).

363 Spatial interpolation techniques are based on known correlations between biophysical features (e.g., 364 vegetation cover, species distribution) and social data (e.g., attitudes toward residential 365 development, local values for conservation). However, the assumptions implicit in the application 366 of data from one region to another introduce uncertainty and error in analysis (Eicher and Brewer, 367 2001; Gotway and Young, 2002). An alternative is for multiple development and environmental 368 agencies to work together at the sub-regional or regional scale to collect social data within a 369 consistent methodology. The Australian Government's Strategic Assessment process enables the assessment of development impacts at the regional scale, and if implemented elsewhere, presents an opportunity for primary social data to be collected at the regional scale that is of interest to multiple planning and environmental agencies.

374 Collection of social data should account for the fact that the effect of social dynamics will differ according to the scale of analysis; the biodiversity of landscapes, catchments and properties will all have different social drivers. Furthermore, some social issues may not have been revealed via regional survey methods, and planning agencies may need to undertake more detailed analysis in areas where developments are likely to have the highest social and/or environmental impact. Some of these cross-scale issues can be overcome by state and national planning authorities working in partnership with local government in order to link social data collected as part of municipal surveys to social data collected through sub-regional or regional surveys.

It can be challenging to assess how strongly social matters influence biodiversity because of the complexity of individual and group processes (Pannell and Vanclay, 2011). Strategic Assessments may therefore need to make greater allowance for the complex associations between social values, attitudes, behaviours and environmental outcomes, rather than rely on proven causal relationships 
(Biggs et al., 2011; Johnson et al., 2013). This would provide a stronger role for self-reports of 388 attitude, impacts and risks in the assessment process. There is a risk, however, that focusing too 389 much on social data (that are often only indirectly associated with environmental outcomes) could expose the consent authority to legal challenge, since the Government's legislated authority extends only to the protection of MNES. We therefore do not argue that these social data should necessarily be given equal weight as biophysical factors, but rather that their influence be applied systematically in context of such factors.

\subsection{Organisational implementation}

The culture of proponent organisations and regulatory authorities is likely to influence how successfully social data are incorporated into the Strategic Assessment process. Organisations that are used to dealing predominantly with biophysical information can perceive that social information is less useful for decision-making because it is 'soft' or imprecise (see for example Bojórquez Tapia et al., 2003). Resistance to the use of social data in assessing biodiversity impacts may need

401 to be combatted by addressing this perception (Brechin et al., 2002; Robertson and Hull, 2001). Good leadership and providing avenues for civil servants and proponents to express any concerns can be proactive ways of bringing about cultural change.

As most SEA practitioners are used to evaluating biophysical impacts of a proposal, there may be a lack of skills and expertise in integrating these with relevant social data. This could result in misinterpretation of social data as it relates to biodiversity impacts, or the neglect of useful social information altogether. This can be addressed through targeted training for both proponents and assessment staff on (1) what kinds of social data are relevant for different assessments, (2) methods on collecting social data, and (3) how to interpret social data as it relates to conservation outcomes. 
412 Stakeholder engagement can be another potential challenge to successfully integrating social data 413 into the Strategic Assessment process. To avoid a number of the pitfalls associated with stakeholder 414 engagement (see Cooke and Kothari, 2001), the scope and purpose of the engagement need to be 415 articulated clearly to stakeholders at the outset of the project to ensure that societal expectations 416 regarding data use are accurate. Following data collection, translation of social data relevant to the 417 assessment to stakeholders and general public must be done carefully, with clear communication 418 about the implications of the information. If social data are not made accessible and understandable 419 to stakeholders and decision-makers they are unlikely to influence the decision-making process 420 (Biggs et al., 2011; Knight et al., 2006).

Finally, decision outcomes may not reflect the new information even if social data are integrated well into reports and documents that form the Strategic Assessment. Macintosh (2013, p. 542) notes that improved information alone may not generate better environmental decisions in EIA, since decisions are largely the product of "values, power and incentives". While the iterative and collaborative decision-making approach of Strategic Assessment goes some way to address this, ultimately the risk remains that little weight is given to social data in decision-making. Nevertheless, addressing the points listed above is likely to ensure that social data more adequately informs Strategic Assessments.

\section{General principles for considering conservation-relevant social data in SEA}

A number of general policy principles can be derived from our study of the Strategic Assessment process in Australia that relate to SEA applications globally. There is great variation in SEA legislation, methodologies and procedures internationally and it is beyond the scope of this paper to review these here (but see Tetlow and Hanusch, 2012 for a discussion). Nevertheless, whether or not SEA is perceived as a rational way of evaluating environmental impacts or a loosely 
438 implemented framework for developing collaborative sustainability solutions (c.f. Tetlow and 439 Hanusch, 2012), most SEA contexts will contain opportunities to integrate social data in the 440 assessment of conservation outcomes.

\subsection{A stepwise approach to considering key social matters related to biodiversity in SEA practice}

A number of logical steps should be followed by both the parties preparing reports to be assessed and those performing an assessment. First, it is important that SEA practitioners "consider biodiversity values and uses within the plan area” (Treweek et al., 2005, p. 188). Once relevant biodiversity matters are identified (either on social or biological grounds), the social determinants of conservation within the landscape need to be considered (see Section 4 for examples). The next consideration is then to understand how relevant social conditions are likely to change with the implementation of a plan.

Assessment of threats and opportunities for conservation that are associated with a policy, plan or program is the perhaps the most significant stage within an SEA. This can be done by considering three landscape categories. The first is existing protected areas, which are the cornerstone of most conservation efforts. Questions that should be asked include (i) are they likely to persist in providing conservation outcomes into the future? (ii) what is the current and likely future level of social acceptability? and (iii) how threatened are they by shifting community attitudes and changing behaviours? The second landscape category is biodiversity outside of formal protected area networks. Questions to be asked of these areas include (i) what social capital (Pretty and Smith, 2004) exists to maintain and enhance biodiversity on private land? and (ii) how might this change 460 with the implementation of the policy, plan or program? If a large proportion of the biodiversity 461 being considered under a SEA is present on private land, answers to such questions may be crucial to conservation outcomes. The final landscape category is newly created protected areas. This is becoming increasingly important with the rapid adoption of biodiversity offsetting in SEA. The 
capacity of new conservation reserves to meet biodiversity outcomes is dependent to a large degree on their design, management and political and community acceptability. Moreover, creation of formal reserves as offsets may not lead to better biodiversity outcomes as this shift in land tenure may promote abdication of responsibility by landholders. An understanding of community attachment and stewardship may be very useful in determining where to position such biodiversity offset areas.

\subsection{Operational guidance}

One key recommendation for effective integration of social data with environmental data in the SEA process is that both should be collected concurrently throughout the data collection stages as a requirement of the proponent. The kind of social data collected will depend on the context of the plan, with secondary data collection (e.g., review of grey and peer-reviewed literatures) possibly sufficient in communities frequently surveyed by social scientists. However, the use of public participation techniques to elicit social values (such as PPGIS) has the added advantage of achieving other outcomes than simply enhancing biodiversity protection. These include learning outcomes (both social and technical), governance outcomes (such as enhancing stakeholder participation in decision-making), development outcomes (influencing the design of plans), and attitudinal and value changes (promoting sustainability within the community) (Tetlow and Hanusch, 2012). The analysis of social and environmental data together can also help identify socio-ecological tipping points, where activities undertaken can cause phase changes to natural and social systems. Such complex concepts will require the collaboration of interdisciplinary teams of practitioners and the integration of conservation and social impact reports.

SEA practitioners should also look for existing opportunities in legal structures for the inclusion of social data related to conservation outcomes, as this article has demonstrated for the Australian 
context. Indeed, a robust analysis of social values provides decision makers with increased certainty

491 that decisions regarding protection of environmental assets are more legally defendable. Since the overarching purpose and language of SEA is broad and inclusive of environmental, social and economics elements of sustainability, most frameworks for the application of SEA contain relevant clauses or operational practices that can support the inclusion of these data.

\section{Conclusion}

Incorporating social determinants of conservation success in SEAs of land use plans can strengthen conservation outcomes. Failure to do so can lead to unforseen negative biodiversity impacts following changes in social dynamics that result from actions undertaken according to policies, plans or programs. SEA as a policy mechanism offers great promise because of its widespread use, broad scope (considering more diffuse upstream causes of environmental impacts) and flexible

503 administration. Although many questions remain about the practical application of social data to 504 SEA, our case study of the Australian Strategic Assessment process demonstrates that opportunities exist within current legal processes for adjustments that will enable improved conservation outcomes. Since it is widely accepted that successful conservation relies on the social feasibility of conservation actions, legal mechanisms providing protection for biodiversity cannot afford to be

508 insular and restrictive, both for the sake of long term environmental conservation and the integrity 509 of the legislation. Stronger collaboration between conservation scientists and environmental 510 regulators is required to advance the contribution of social data to strengthen conservation outcomes 511 in legislated SEA processes both in Australia and internationally.

\section{Acknowledgements}

514 This article is a product from a workshop on the theme of conservation opportunity, held on 515 Stradbroke Island, Queensland, 23 - 26 April 2013. Funding for the workshop and resulting 
research is from the Australian Government's National Environment Research Program, and the Australian Research Council Centre of Excellence for Environmental Decisions. The authors would like to thank Steve Mercer for his constructive feedback on an earlier version of this manuscript.

\section{References}

Ashe, J., Marsden, S., 2011. SEA in Australia, in: Sadler, B., Aschemann, R., Dusik, J., Fischer, T.B., Partidário, M.R., Verheem, R. (Eds.), Handbook of Strategic Environmental Assessment. Earthscan, London, pp. 21-35.

Ban, N.C., Mills, M., Tam, J., Hicks, C.C., Klain, S., Stoeckl, N., Bottrill, M.C., Levine, J., Pressey, R.L., Satterfield, T., Chan, K.M., 2013. A social-ecological approach to conservation planning: embedding social considerations. Front. Ecol. Environ. 11, 194-202.

Biggs, D., Abel, N., Knight, A.T., Leitch, A., Langston, A., Ban, N.C., 2011. The implementation crisis in conservation planning: could “mental models” help? Conserv. Lett. 4, 169-183.

Bojórquez-Tapia, L., Brower, L., Castilleja, G., Sanchez-Colon, S., Hernandez, M., Calvert, W., Diaz, S., Gomez-Priego, P., Alcantar, G., Melgarejo, E., Solarez, M., Gutierrez, L., Juarez, M., 2003. Mapping expert knowledge: redesigning the monarch butterfly biosphere reserve. Conserv. Biol. 17, 367-379.

Brechin, S., Wilshusen, P., Fortwangler, C., West, P., 2002. Beyond the square wheel: toward a more comprehensive understanding of biodiversity conservation as social and political process. Soc. Nat. Resour. 15, 41-64.

Brouwer, R., Martin-Ortega, J., Berbel, J., 2010. Spatial preference heterogeneity: A choice experiment. Land Econ. 86, 552-568.

Brown, G., 2005. Mapping Spatial Attributes in Survey Research for Natural Resource Management: Methods and Applications. Soc. Nat. Resour. 18, 17-39.

Brown, G., 2012. Public Participation GIS (PPGIS) for regional and Environmental Planning: reflections on a decade of Empirical research. URISA J. 25, 7-18. 
Brown, G., Raymond, C.M., 2014. Methods for identifying land use conflict potential using participatory mapping. Landsc. Urban Plan. 122, 196-208.

Brown, G., Reed, P., 2012. Values Compatibility Analysis: Using Public Participation Geographic Information Systems (PPGIS) for Decision Support in National Forest Management. Appl. Spat. Anal. Policy 5, 317-332.

Brown, G., Weber, D., 2011. Public Participation GIS: A new method for national park planning. Landsc. Urban Plan. 102, 1-15.

Brown, T., 1984. The Concept of Value in Resource Allocation. Land Econ. 60, 231-246.

Bryan, B.A., Raymond, C.M., Crossman, N.D., King, D., 2011. Comparing spatially explicit ecological and social values for natural areas to identify effective conservation strategies. Conserv. Biol. 25, 172-81.

Chanchitpricha, C., Bond, A., 2013. Conceptualising the effectiveness of impact assessment processes. Environ. Impact Assess. Rev. 43, 65-72.

Cooke, B., Kothari, U., 2001. Participation: the New Tyranny? Biddles, UK.

Curtis, A., Byron, I., MacKay, J., 2005. Integrating socio-economic and biophysical data to underpin collaborative watershed management. J. Am. Water Resour. Assoc. 41, 549-563.

Curtis, A., McDonald, S., Mendham, E., Sample, R., 2008. Understanding the social drivers for natural resource management in the Wimmera region, Report No. 46. Institute for Land, Water and Society, Charles Sturt University, Albury.

Department of Sustainability, Environment, Water, Population and Communities, 2012. A guide to undertaking strategic assessments. Australian Government, Canberra. http://www.environment.gov.au/resource/guide-undertaking-strategic-assessments (accessed 4 February 2014).

Early, G., 2008. Australia's National Environmental Legislation and Human/Wildlife Interactions. J. Int. Wildl. Law Policy 11, 101-155.

Ecologically Sustainable Development Steering Committee, 1992. National Strategy for Ecologically Sustainable Development. http://www.environment.gov.au/resource/national-

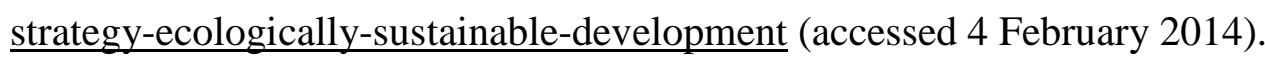


Eicher, C.L., Brewer, C.A., 2001. Dasymetric mapping and areal interpolation: Implementation and evaluation. Cartogr. Geogr. Inf. Sci. 28, 125-138.

Gauthier, M., Simard, L., Waaub, J.-P., 2011. Public participation in strategic environmental assessment (SEA): Critical review and the Quebec (Canada) approach. Environ. Impact Assess. Rev. 31, 48-60.

Gotway, C.A., Young, L.J., 2002. Combining Incompatible Spatial Data. J. Am. Stat. Assoc. 97, 632-648.

Guerrero, A.M., Knight, A.T., Grantham, H.S., Cowling, R.M., Wilson, K.A., 2010. Predicting willingness-to-sell and its utility for assessing conservation opportunity for expanding protected area networks. Conserv. Lett. 3, 332-339.

Guerrero, A.M., McAllister, R.R.J., Corcoran, J., Wilson, K.A., 2013. Scale mismatches, conservation planning, and the value of social-network analyses. Conserv. Biol. 27, 35-44.

International Association for Impact Assessment (2002) Strategic Environmental Performance Criteria, Special Publication Series No. 1. Available at http://www.iaia.org/publicdocuments/special-publications/sp1.pdf (accessed 25 June 2014).

Ives, C.D., Kendal, D., 2014. The role of social values in the management of ecological systems. J. Environ. Manage. 144, 67-72.

Johnson, F., Williams, B., Nichols, J., 2013. Resilience Thinking and a Decision-Analytic Approach to Conservation: Strange Bedfellows or Essential Partners? Ecol. Soc. 18, 27.

Jones, C., Baker, M., Carter, J., Jay, S., Short, M. and Wood, C. (2005). Conclusion, in: Jones, C., Baker, M., Carter, J., Jay, S., Short, M. and Wood, C. (Eds.), Strategic Environmental Assessment and Land Use Planning. Earthscan, London.

Kareiva, P., Marvier, M., 2012. What Is Conservation Science? Bioscience 62, 962-969.

Knight, A., Cowling, R., Rouget, M., Balmford, A., Lombard, A.T., Campbell, B.M., 2008. Knowing But Not Doing: Selecting Priority Conservation Areas and the Research Implementation Gap. Conserv. Biol. 22, 610-617.

Knight, A.T., Cowling, R.M., 2007. Embracing opportunism in the selection of priority conservation areas. Conserv. Biol. 21, 1124-1126. 
Knight, A.T., Cowling, R.M., Campbell, B.M., 2006. An Operational Model for Implementing Conservation Action. Conserv. Biol. 20, 408-419.

Lesslie, R., 2012. Mapping our priorities - innovation in spatial decision support, in: Figgis, P., J, F., Irving, J. (Eds.), Innovation for 21st Century Conservation. Australian Committee for IUCN Inc., pp. 156-163.

Lobos, V., Partidario, M., 2014. Theory versus practice in Strategic Environmental Assessment (SEA). Environ. Impact Assess. Rev. 48, 34-46.

Macintosh, A., 2009. Australia’s National Environmental Legislation: A Response to Early. J. Int. Wildl. Law Policy 12, 166-179.

Macintosh, A., 2013. Strategic environmental assessment: a solution to the problems associated with project-based environmental impact assessment? Aust. Environ. Rev. 541-546.

Marsden, S., 2013. Strategic environmental assessment in Australian land-use planning. Environ. Plan. Law J. 30, 422-433.

Mendham, E., Curtis, A., 2010. Taking Over the Reins: Trends and Impacts of Changes in Rural Property Ownership. Soc. Nat. Resour. 23, 653-668.

Mendham, E., Curtis, A., Millar, J., 2012. The natural resource management implications of rural property turnover. Ecol. Soc. 17, 5.

Morrison-Saunders, A., Fischer, T.B., 2006. What is wrong with EIA and SEA anyway? A sceptic's perspective on sustainability assessment. J. Environ. Assess. Policy Manag. 8, 19-39.

Ng, K.L., Obbard, J.P., 2005. Strategic environmental assessment in Hong Kong. Environ. Int. 31, 483-492.

Nielsen-Pincus, M., Goldberg, C.S., Pocewicz, A., Force, J.E., Waits, L.P., Morgan, P., Vierling, L., 2010. Predicted effects of residential development on a northern Idaho landscape under alternative growth management and land protection policies. Landsc. Urban Plan. 94, 255263.

Noble, B., Gunn, J., Martin, J., 2012. Survey of current methods and guidance for strategic environmental assessment. Impact Assess. Proj. Apprais. 30, 139-147. 
625 Pannell, D., Vanclay, F., 2011. Changing Land Management: Adoption of New Practices by Rural Landholders. CSIRO Publishing.

627

628

629

630

631

632

633

634

635

636

637

638

639

640

641

642

643

644

Pannell, D.J., Marshall, G.R., Barr, N., Curtis, A., Vanclay, F., Wilkinson, R., 2006. Understanding and promoting adoption of conservation practices by rural landholders. Aust. J. Exp. Agric. 46, 1407-1424.

Partidário, M., 2000. Elements of an SEA framework—improving the added-value of SEA. Environ. Impact Assess. Rev. 20, 647-663.

Partidário, M.R., 1996. Strategic environmental assessment: key issues emerging from recent practice. Environ. Impact Assess. Rev. 16, 31-55.

Pasquini, L., Twyman, C., Wainwright, J., 2010. Toward a conceptual framework for blending social and biophysical attributes in conservation planning: a case-study of privately-conserved lands. Environ. Manage. 46, 659-70.

Pretty, J., Smith, D., 2004. Social Capital in Biodiversity Conservation and Management. Conserv. Biol. 18, 631-638.

Raymond, C.M., Brown, G., 2011. Assessing conservation opportunity on private land: Socioeconomic, behavioral, and spatial dimensions. J. Environ. Manage. 92, 2513-2523.

Raymond, C.M., Curtis, A., 2013. Mapping community values for regional sustainability in the Lower Hunter region of NSW. NERP Landscape and Policy Research Hub, The University of Tasmania.

Rauschmayer, F., Risse, N., 2005. A framework for the selection of participatory approaches for SEA. Environ. Impact Assess. Rev. 25, 650-666.

Ridges, M., 2006. The Material Component of the Aboriginal Cultural Landscape: Mapping Country Through Predictive Modelling, in: Proceedings of the 12th ANZSYS Conference Sustaining Our Social and Natural Capital. Katoomba, NSW Australia, pp. 105-113.

Robertson, D.P., Hull, R.B., 2001. Beyond Biology: toward a More Public Ecology for Conservation. Conserv. Biol. 15, 970-979.

Sadler, B., 1996. International Study of the Effectiveness of Environmental Assessment, Final Report. Canadian Environmental Assessment Agency, Ottawa. 
Seymour, E., Curtis, A., Pannell, D., 2010. Understanding the role of assigned values in natural resource management. Australas. J. Environ. Manag. 17, 142-153.

Sherrouse, B.C., Clement, J.M., Semmens, D.J., 2011. A GIS application for assessing, mapping, and quantifying the social values of ecosystem services. Appl. Geogr. 31, 748-760.

Slootweg, R., Vanclay, F., van Schooten, M., 2001. Function evaluation as a framework for the integration of social and environmental impact assessment. Impact Assess. Proj. Apprais. 19, $19-28$.

Tetlow, M.F., Hanusch, M., 2012. Strategic environmental assessment: the state of the art. Impact Assess. Proj. Apprais. 30, 15-24.

Ticehurst, J.., Curtis, A., Merritt, W.S., 2011. Using Bayesian Networks to complement conventional analyses to explore landholder management of native vegetation. Environ. Model. Softw. 26, 52-65.

Treweek, J., Therivel, R., Thompson, S., Slater, M., 2005. Principles for the Use of Strategic Environmental Assessment As a Tool for Promoting the Conservation and Sustainable Use of Biodiversity. J. Environ. Assess. Policy Manag. 07, 173-199.

United Nations Environment Programme, 2002. Guidelines for incorporating biodiversity-related issues into environmental impact assessment legislation and/or process and in strategic environmental assessment. http://www.cbd.int/decision/cop/default.shtml?id=7181 (accessed 4 February 2014).

Uprety, B.K., 2005. Biodiversity considerations in strategic environmental assessment: A case study of the Nepal Water Plan. J. Environ. Assess. Policy Manag. 7, 247-266.

Vanclay, F., 2003. International principles for Social Impact Assessment. Impact Assess. Proj. Apprais. 21, 5-12.

Vanclay, F., 2004. The triple bottom line and impact assessment: How do TBL, EIA, SIA, SEA and EMS relate to each other? J. Environ. Assess. Policy Manag. 6, 265-288.

Voinov, A., Bousquet, F., 2010. Modelling with stakeholders. Environ. Model. Softw. 25, 12681281. 
680 Whitehead, A.L., Kujala, H., Ives, C.D., Gordon, A., Lentini, P.E., Wintle, B.A., Nicholson, E., 681 Raymond, C.M., in press. Integrating biological and social values when prioritizing places for 682 biodiversity conservation. Conserv. Biol.

683

684 
Figure 1. Strategic Assessment process under the EPBC Act (adapted from DSEWPAC, 2012).

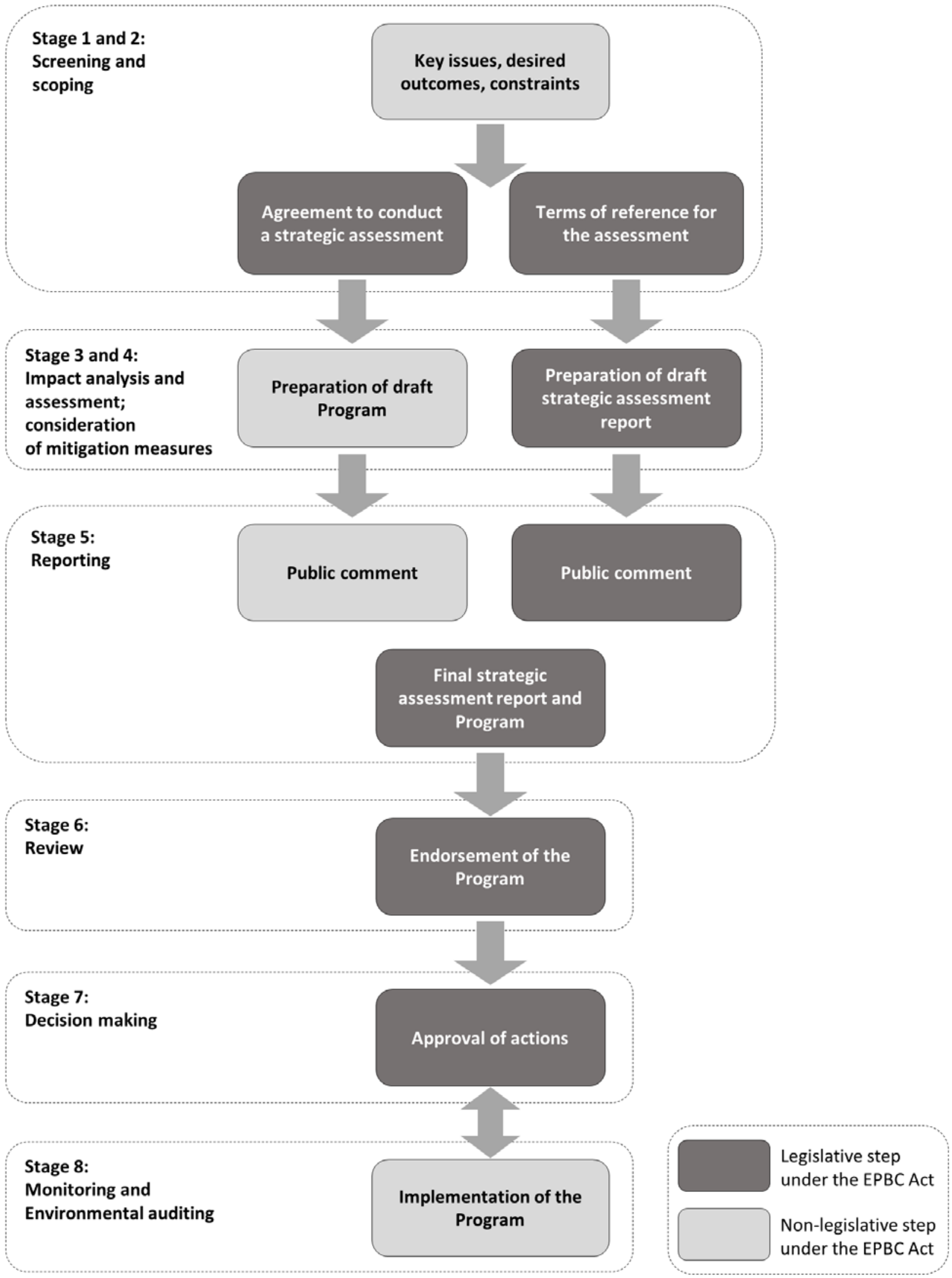

